\title{
The Establishment of Education System Based on the Cultivation of College Students' Innovation Ability
}

\author{
Jie Li \\ Xi'an Fanyi University, 710105 Xi'an China \\ 2876601717@qq.com
}

Keywords: Innovation ability; Education system; College students

\begin{abstract}
With the development of science and education, the implementation of the strategy of talent powerful nation, the audience of higher education is becoming more and more popular. Whether students choose to attend school or business units in the new choice, the comprehensive level of college and talent training is the key to select the content of the study. Students' innovation ability determines the level of students' comprehensive quality. The cultivation of students' innovative ability is the key factor to improve the teaching level in Colleges and universities.
\end{abstract}

\section{Introduction}

With the development of social economy and people's living standard, people pay more and more attention to education. In recent years, the number of college students in our country is higher than that of the major. Since these years, the problem of the employment of college graduates is becoming more and more serious, which makes the major colleges and universities begin to examine the problems of education and teaching and talent cultivation. The talent market employment competition intensified, the importance of cultivating talents with innovation ability caused national attention to the education sector, calling for the college education to cultivate students' innovation ability as the core, systematic and long-term development of innovative education. Requirements of major colleges and universities to update the management concept, the reform of the education management system at this stage, optimize the teaching methods of teachers, the establishment of a sound education and teaching system.

\section{How to Cultivate Students' Innovative Ability}

What Is Innovation Ability. Broadly speaking, the innovation ability refers to the knowledge and practice in daily life, from the aspects of art, science and technology, new ideas, inventions or way of thinking, to create favorable social and ecological value, economic value. Everyone has a different understanding of innovation, Robert. Sternberg's view that human intelligence is connected to three sides of the combination relation, intelligence is the unity of the combination of divergent thinking, also known as the two-degree thinking is the core of creative thinking. His understanding of the creative, individual in the face of new problems and treatment, formed by the integration of different ideas or creative insight. The establishment of the evaluation method for the cultivation of innovation ability and innovation ability and Peng Jianbo have different views and interpretation, he also proposed innovation ability enhancement rate formula, and analyzed using the evaluation method of the formula and the significance of innovation ability. But whether has the broad vision, independent thinking, rich knowledge, rich imagination and practical ability, the ability in five different grades (excellent, good, bad and inferior division). Then the fuzzy mathematics method is used to deal with the data, which is the theoretical method of the comprehensive evaluation of the innovation ability of Jin Qin.

How to Cultivate the Development Direction of Innovation Ability. Logical thinking is also an important part of creative thinking. In addition, including divergent thinking, analogy and uniqueness, fluency is the main feature of divergent thinking. The characteristics of the cultivation of divergent thinking ability is the focus on students' ability to improvise, to learn knowledge to draw inferences. When you encounter problems, you must have the opposite thinking and insights, 
there is an instant reaction ability, do not blindly follow the crowd, blindly follow the trend of view. According to the existing information, to play the association and imagination, to find the key to the problem, to seek the best operation process and results, to solve practical problems. In the process of finding the best solution, we can communicate with others to discuss and exchange experience. In the process of communication, independence, to maintain their own thinking not others, to believe that they live direct feeling of things, to inspire the simplest thinking of thinking about things.

Logical thinking more attention to the use of the information of the known information, the cumulative integration, through the play of divergent thinking and imagination, to make an extension of the known information and comprehensive judgment. Different people have different ways of thinking, which have different thinking ability, want to carry on thinking from the root of innovation, it should start from the development of innovation and thinking ability. In the process of thinking, the most critical issues cannot be lost, because only individual thinking can produce creative thinking.

The cultivation of students' creative ability is a comprehensive work, which cannot meet the requirements of the cultivation of innovative ability through the cultivation of creative thinking. In addition to the requirements of innovative thinking, the cultivation of innovative personality is also essential, only the students have a certain personality quality, innovation ability to be able to develop. The curiosity of students must exist, to promote the depth of thinking ability, only students constantly active thinking, innovative thinking became possible, independent thinking and action, is the key factor to promote innovation. From the objective conditions, the rich imagination is essential, through the rich imagination to explain the imagination, and then according to the actual to confirm their own imagination. In a word, students' subjective initiative and independence is the key factor to cultivate students' innovative personality.

Students' ability to solve problems by using the cognition and law of objective things is called the innovation wisdom. On the one hand, innovation wisdom refers to the life experience of the highly condensed, through a variety of philosophical theory and learning strategy of doing things with the depth and height of the thought idea, using philosophy to provide a theoretical basis. On the other hand, through the accumulation of experience, in the continuous experience and practice of social action, to gain experience and experience, enrich their knowledge and experience, to help themselves get the greatest practical benefits.

In the process of innovation, to guide people to analyze the problem, to help people to solve the problem of specific methods and steps called innovative methods. As a creative activity, innovative methods need specific methods and tools, which is one of the essential contents of the cultivation of students' creative ability. In simple terms, in learning, students in the learning method of the original, according to the characteristics of their own thinking and practical needs, in accordance with the idea of his thoughts and solve problems, improve the methods of learning, innovative learning ideas, find their own. The learning method that is beneficial to the improvement of learning efficiency is the innovative method.

The cultivation of innovative ability is not only to cultivate students' innovative thinking, innovative personality, innovative wisdom and innovative methods, it is difficult to rely on these several innovations. The above is just the idea of cultivating students' innovative ability. Require students to have their own understanding and understanding of these aspects, active and conscious participation in innovation activities, and constantly deepening thinking and accumulated experience, it is possible to achieve innovation.

Problems Existing in Cultivating Students' Innovative Ability in Colleges and Universities. At the present stage, the education system of the vast majority of colleges and universities in our country is more disadvantageous to the cultivation of students' creative ability. The existing teaching system cannot provide favorable conditions for the cultivation of students' innovative ability, even to a certain extent, it will hinder the development of students' creative ability.

Why is it that the existing college education model will hinder the development of students' innovation ability? To have the following reasons. The first point, at the present stage, the teaching 
mode of college is mainly carried out in the form of teaching class, students' personality cannot be played out well, cannot be used in different ways to cultivate students' innovative ability. Especially in class teaching, the teachers remember that every student has a certain degree of difficulty, more likely not to understand the personality characteristics of each student. The educational model of class education will form a thinking pattern, which has a great influence on the students' thinking ability and the activity of thinking.

The second point, the teacher's authority. Due to the long-term influence of the thinking mode of examination oriented education, students generally have a look to the authority of teachers. Most of the students are accustomed to using the teacher's standards to regulate themselves, whether in the way of thinking or learning methods, students cannot jump out of the scope of teachers, to maintain independent thinking. It is difficult to complete the learning without the teacher's guidance and help, solve the problems encountered in the learning process, students and teachers will be long-term knowledge as the absolute authority, the loss is not only the ability of independent thinking. At the same time, it has lost the dialectical critical thinking and critical spirit, without criticism and doubt, there is no innovation.

Third, the students themselves lazy. Students have been accustomed to the scope of the teacher designated focus, outside the scope of knowledge content, because the exam is not involved, students will not take the initiative to learn and think. Learn to get rid of high pressure and high strength of University High School Students' learning mode, to a great extent to relax, and some wrong understanding, think the university study should be free and easy, reduce students' self-learning ability, and development of independent innovation ability is limited.

The fourth point, the teaching evaluation system is not perfect. The evaluation of students' innovation ability is generally done by the teachers' team, the department leaders or experts. This evaluation system is not able to achieve a comprehensive and objective evaluation of students' innovative ability, instead of the students' self-consciousness development. The main standard of innovative capability evaluation of student achievement, from four aspects of students Dezhitimei, objective standard and not the study of students' innovation ability. Such evaluation methods, but also very likely to hit some of the innovative ability, but poor students' enthusiasm, unable to form innovative motivation, confidence building. To cultivate the innovation ability of college students, the university must re-examine the current education mode, reform the teaching system, establish the teaching system of the innovation ability of the students.

\section{Establishing the Education System Based on the Cultivation of College Students' Innovation Ability}

The orderly combination of various educational elements in the educational system or the various educational institutions which are connected with each other is called the educational system. The meaning of education system also has broad sense and narrow sense. The general education system includes not only the structural system of education, but also the contents of education management, education and scientific research, teacher training, talent forecast, fund raising, course materials and so on. Narrow educational system is also the main content of this paper, including the establishment and change of educational structure system.

Theoretical Basis for the Construction of Innovative Education System. Education cannot be separated from the society. Whether from the relative independence of education itself or the subjective initiative of education, education should be closely related to the social reality. The essence of all kinds of education at all levels should return to the essence of the society, so the subject of education should take more consideration of the actual relationship between social organization, enterprise unit and individual. From the perspective of multi angle, including the school, it is beneficial to the cultivation of students' innovative ability and the pursuit of the diversification and comprehensiveness of the main body of education in the form of education.

From the view of the majority of the students educated subject, according to the actual situation of students, students from the individual physical and mental development, basic knowledge, ability and quality, and other aspects of the objective factors of the external environment, give full play to 
the initiative of students. To cultivate the students to improve the educated subject, high education system, first of all, to let students learn autonomous learning consciousness, fully mobilize students' learning initiative; Second, actively cultivate students' interests and hobbies, learn to choose their favorite professional and interest; Finally, to cultivate students' sense of responsibility, so that students grow into a responsible person, the person in charge of the good youth. As a student, only to be able to live independently, independent learning, independent pursuit of research ability, can be expected to become independent, innovative talent.

In the aspect of the subjectivity of teaching, teacher educators fully occupy the dominant position of, play a guiding role to the students. Teaching is the main body of school and teachers, we cannot use the passive or active to describe the teaching relationship with the student body. The teacher occupies the main position in teaching, only give full play to the main role, to education with rich spirit of the theme of students. Only the teachers and students to give full play to their autonomy, to promote the creation of innovative talents, to promote its development, which is the main teaching requirements.

The Design Features of the Education System under the Cultivation of Innovative Ability. First of all, pay attention to the cultivation of students' sense of innovation and entrepreneurship; Secondly, the development of a series of curriculum system in a prominent position; Third, to cultivate students' ability to imitate, so that they can obtain more perceptual experience by imitating the actual combat mode; Fourth, the solid academic research as a support point; Finally, through the innovation ability of teachers and students to directly induce the innovation and entrepreneurial activities.

\section{The Significance of Cultivating Students' Innovation Ability Education System}

The education system under the ability training mainly trains the student's ability of innovation, the innovation skill and the sense of innovation. To pay attention to the combination of practice and innovation, and to further develop a high-quality, innovative and comprehensive talents of the education system. The new education system not only expands the research field of innovation education in our country, but also enriches the theoretical research on talents training in the field of higher education. For China's reform and modernization of higher education provides a navigation beacon for the community to train more excellent innovative talents, better meet the requirements of international education. The important part of the education system is its scientific design concept and effective practice, only with this system model, in order to better provide innovative talents for the country and society. The input of creative talents is of great significance to the improvement of international status and the development of high level. It is of great significance to establish the educational system.

\section{Conclusion}

The plan to cultivate the students' innovative ability has its inevitable significance. Only let these talents to better integrate into the community, for the continuous development of society, the fierce competition between enterprises to provide an advantage for our country's comprehensive national strength to lay a solid foundation. It is very important to cultivate innovative talents, perfect, stable, and optimize the system of cultivating the innovative talents. Only the establishment of the educational system adapting to the development of innovative talents can promote the further development of colleges and universities, and win the competition in the fierce society.

\section{References}

[1] Zhu Xiangdong, the establishment of education system based on the cultivation of College Students' innovation ability, frontier, journal, 2013-06-01

[2] Qin Jing, the establishment of education system based on the cultivation of College Students' innovation ability, Heilongjiang science, journal, 2015-02-15 
[3] Liao Zhihao, research on the cultivation of innovative talents of science and technology based on quality model, East China Normal University, doctoral dissertation, 2012-05-01

[4] Zheng Ying, construction and application of the competency model of college students of Wuhan University, doctoral thesis, 2013-05-01

[5] Tong Xiaoling, research on the innovation and entrepreneurship education system of the research university, Wuhan University of Technology, doctoral dissertation, 2012-10-08

[6] Jiang Zhibin, research on the construction of college student cadres in the new period, Southwestern University, doctoral dissertation, 2011-10-20

[7] Song of the handsome, engineering university entrepreneurship education model research, HeFei University of Technology, doctoral dissertation, 2014-11-01

[8] Rui 8, research university entrepreneurship education system in information age, Doctoral Dissertation of Shaanxi Normal University, 2014-06-01

[9] Zhang Yan, research on Ideological and political education in Colleges and universities, Southwestern University, doctoral dissertation, 2013-04-06

[10]Li Donghang, research on the system of higher education streaming system, Huazhong Normal University, doctoral dissertation, 2015-03-01 